\title{
Physicians and federal government in need of self-examination
}

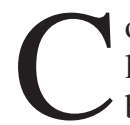
onsider it a day of eloquent laments. It featured a plea for a bit of old-fashioned "human" doctoring as well as a stirring condemnation of the federal government's disengagement from health care - laments, in short, for a Canada that may no longer exist.

The former emerged in the valedictory address of Dr. John Haggie, as he stepped off the national stage as president of the Canadian Medical Association during its 145th annual general meeting, being held in Yellowknife, Northwest Territories. The latter emerged from former president Dr. Jeff Turnbull during a special session to address future CMA advocacy options in light of the federal government's decision to essentially abandon any pretense that it will seek to ensure equity in health services across the country.

Haggie told delegates that his year in office and his travels across the country made it clear Canada's doctors are in need of "some self-examination of how we practise our profession."

"A few decades ago, cutting-edge medicine was all going to be technical, reliant on ever bigger, better and more expensive gizmos." Yet, he asked, "what is the benefit for an elderly patient whose health status may be regarded as technological success if at the same time that's a therapeutic failure?"

"What we are looking at now is the era of low-intensity health care, not the big glamorous investments, not the multimillion dollar machines and the very expensive procedures, but small incremental amounts of money invested in the community, of point of care where it makes a difference."

"I'm not suggesting that we turn back the clock," Haggie added. "We couldn't practise medicine the way we do without the use of modern technology."

"At the same time, we have got to go back to the idea of putting hands on the

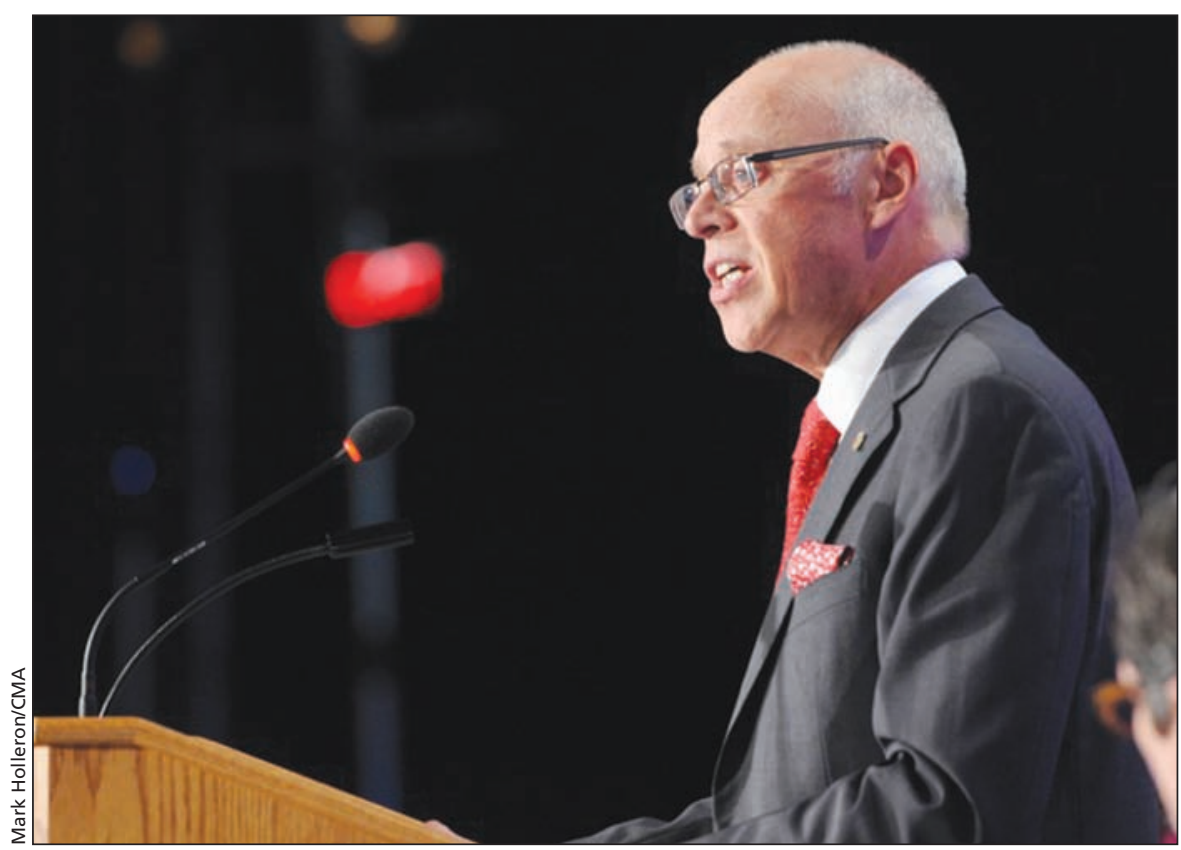

Physicians have to remember what they were "taught in medical school about how to talk to our patients, to listen to them, and the power of touch," says outgoing CMA President Dr. John Haggie.

patient and establishing physical contact in a way that cements the therapeutic, not just simply hide behind our white coats and our scrubs and vanish into the realms of the latest new machine. We have to remember what we were taught in medical school about how to talk to our patients, to listen to them, and the power of touch."

"We are a profession, not because of how we are compensated. We profess, we espouse, an oath, that each of us has taken," Haggie added.

Asked at a later press conference if he was concerned that Canadian physicians are losing their professionalism, Haggie replied that "the relationship between a physician and the patient is core to medicine. It is a fundamental element of professionalism."

No less compelling was Turnbull's deft dissection of the Health Minister Leona Aglukkaq's remarkable assertion that the federal government has done its bit to ensure health equity and fairness by fixing the formula for cash transfers for health care to the provinces through 2024 and that other federal action would be an intrusion on provincial flexibility to invest in areas deemed priorities or to deliver health care in a fashion they believe to be optimal (www.cmaj.ca/site/earlyreleases/14aug12 _enough-unhelpful-over-the-top-rhetoric -aglukkaq-says.xhtml).

The federal government's "lack of interest" constitutes a breach of its constitutional responsibilities, its international obligations and its duty to Canadians, Turnbull argued. "The federal government has a critical role to play in facilitating national benchmarks and standards to ensure equity across the country. Regardless of where they live, Canadians should be entitled to comparable levels of care, outcomes and accountabilities."

Instead, efforts to develop panCanadian health strategies to deal with issues like chronic disease are failing 
and drug coverage is widely variable. "Only 8 of 13 jurisdictions provide catastrophic drug coverage by capping costs at a certain level of income."

"Federalism as it is being practised today creates winners and losers, greater disparities, whereas nationbuilding is about leadership, courage, mutual support and equity, and living up to our shared values. I don't want to have supplementary health insurance to travel to BC and I don't want people from PEI to move their parents to Ontario to get hypothetically better health care. We don't need 13 different health care systems."

"This debate is as much about defining Canada as it is about health care. The health care system that once was and that is within our reach again, one that is truly comprehensive, accessible and portable, is a reflection of our values as Canadians, values such as fairness, respect, compassion," Turnbull added. "Are these values now slipping away? Should their importance in our national life wax and wane depending on the government of the day? As a physician and as a Canadian, I sincerely hope not."

Turnbull's remarks led to an intensive debate about whether CMA should be holding the federal government's feet to the fire or concentrating its efforts on trying to achieve health reform by working with the Council of the Federation, which represents the provinces.
Several delegates, such as Dr. Phil Narini of Hampton, Ontario, urged CMA to refocus its efforts on the provinces. Given that the federal government has vacated the field, "why would we waste any time trying to change their mind?" But others, such as Dr. John Maxted, urged that CMA "make the fire hotter" under the feet of the federal government, although Dr. Joel Kettner cautioned that it was his experience as former chief public health officer of Manitoba that scientific, practical, moral and efficiency arguments have all "fallen on deaf ears, when it comes to the federal government." - Wayne Kondro, CMAJ

CMAJ 2012. DOI:10.1503/cmaj.109-4273 